\title{
O DESAFIO DA GESTÃO COMERCIAL EM PUBLICIDADE E PROPAGANDA EM UMA ERA DE INOVAÇÕES E CRIATIVIDADE
}

Gabriel Jose da Silva, Vitor Hugo Paris Kemp, Wesley Grande da Silva, Wilson Roberto Lussari, Agessander Manoel

Universidade do Oeste Paulista - UNOESTE, TCS Gestão Comercial, Presidente Prudente, SP. E-mail: wlussari@unoeste.br; agessandermanoel@hotmail.com

\section{RESUMO}

Hoje em dia se percebe que as empresas usam a publicidade para divulgar seus produtos, ideias e serviços, sendo assim como uma empresa pode se destacar entre as demais, como ela pode ir ao sucesso, se diferenciando nos requisitos. Esta uma tarefa difícil para o Gestor Comercial levar a empresa ao sucesso, criar algo que nunca viram antes, ter uma criatividade que leve a empresa ao topo do mercado.

\begin{abstract}
Nowadays, it is perceived that companies use advertising to advertise their products, ideas and services, so that one company can stand out among the others, how it can go to success, differentiating itself in the requirements. This is a difficult task for the Commercial Manager to lead the company to success, to create something they have never seen before, to have a creativity that leads the company to the top of the market.
\end{abstract}

\section{INTRODUÇÃO}

Uma das grandes dificuldades de um gestor comercial é levar a empresa ao sucesso, sendo assim a empresa pode até ter um produto de qualidade, mas como o nome é pouco conhecido no mercador se torna difícil expandir os negócios.

Uma ferramenta de ajuda ao gestor é a publicidade, com ela o gestor pode construir grandes marcas e levar a empresa a um sucesso.

Como um Gestor ira usar a publicidade, por isso precisamos saber o que é, como funciona, e como se usa ela. A publicidade vem do ato de publicar de divulgar, um produto ou uma empresa para torna lá pública um fato ou ideia. A publicidade é uma técnica de comunicação em massa, sendo muito útil, para divulgar os benefícios e vantagens de um produto ou uma empresa.

Para criarmos uma marca de sucesso, alem de ter um produto de boa qualidade e diferente, tem que usar os meios de comunicação, sendo eles propaganda, anúncios e outras. Mas sendo assim criar uma coisa diferente que atrai o publico, podendo ser uma mensagem simples, mas que chama a atenção deles. A propaganda ela influencia as pessoas, as vezes nós não percebemos, mas ela seduz os sentidos, mexe com os desejos, conversa com o nosso inconsciente e prepõe novas experiências novas atitudes novas ações.

Um gestor que sabe usar a publicidade pode tornar Le uma arma poderosa, podendo proporcionar grandes benefícios, mas se for mal usada pode se tornar um perigo. Sabendo usar ela pode trazer um diferencial para a empresa atingindo uma grande de publico podendo fazer seu produto e a sua empresa a uma diferença entre as demais. Existem muitos veículos de propaganda que um gestor pode usar televisão, radio revistas, jornais, outdoor e muitos outros. Outros meios de comunicação são as empresas que se tem um relacionamento, sendo assim as próprias pessoas fazer uma propaganda para você sem que elas percebam, na forma de indicar para as outras. 
Um gestor tem que ter ideia para criar uma ótima propaganda, definir os objetivos, fazer pesquisar, planejamentos, saber o publico alvo, conhecer a agencia de publicidade que esta indo.

\section{METODOLOGIA}

Para a criação desse projeto desenvolveu-se, primeiramente, pesquisa exploratória. De acordo com Severino (2000, p.123), a pesquisa exploratória é um levantamento de dados sobre o objeto estudado, recomendada quando há pouco conhecimento sobre o problema a ser resolvido. Através desse método foi possível coletar informações mais precisas, obter dados adicionais e identificar o problema do gestor na era da inovação e criatividade.

Durante o levantamento bibliográfico, selecionamos os seguintes livros, Rafael Sampaio. Propaganda de A a Z; Arnold M. Barban; Steven M. Cristol: Frank J. Kopec. A essência do planejamento de mídia; Scharf, Edson Roberto. Administração na propaganda; Gade, Christiane. Psicologia do Consumidor e da Propaganda Tamanaha Paulo e Planejamento de Mídia e Kotler, Philip. Administração de marketing.

\section{RESULTADO}

Nesta seção serão apresentados todos os resultados encontrados com esta pesquisa, realizada a partir de materiais já publicados.

\section{MARKETING E PROPAGANDA NA VISÃO DO GESTOR COMERCIAL}

Para Rafael Sampaio (2003, Pag. 26) a propaganda pode ser definida como " a manipulação planejada da comunicação visando, pela persuasão, promover comportamento em beneficio do anunciante que a utiliza" sendo assim tendo objetivos promocionais (de venda) e expansão, informar e despertar interesse. É um instrumento de ação muito poderosa, capaz de proporcionar benefícios para quem usa.

Segundo Kotler, "Gerentes de marketing precisam tomar inúmeras decisões, desde decisões fundamentais, como que características projetar em um novo produto, quantos profissionais de vendas contratar ou quanto gastar em propaganda, até decisões de menor importância, como o texto e a cor de uma nova embalagem." (KOTLER, 2000, p.27)

Segundo Rafael Sampaio (2003, Pag. 24) por conta de o funcionamento ser simples muitas empresas usam, sendo assim a cada dia ela se tornar mais complexa, com uma alta tecnologia, muita experiência. Sendo assim a cada dia que se passa a propaganda vai evoluindo, cada vez que evolui, o senso do consumidor aumenta, levantando barreiras aprimoradas a cada dia.

"O profissional de marketing deve analisar as causas do declínio e determinar se a demanda poderá ser reestimulada com novos mercados-alvo, com mudanças na característica do produto ou com comunicação mais eficazes. A tarefa do marketing é reverter o declínio da demanda por meio do marketing criativo." (KOTLER, 2000, p.28)

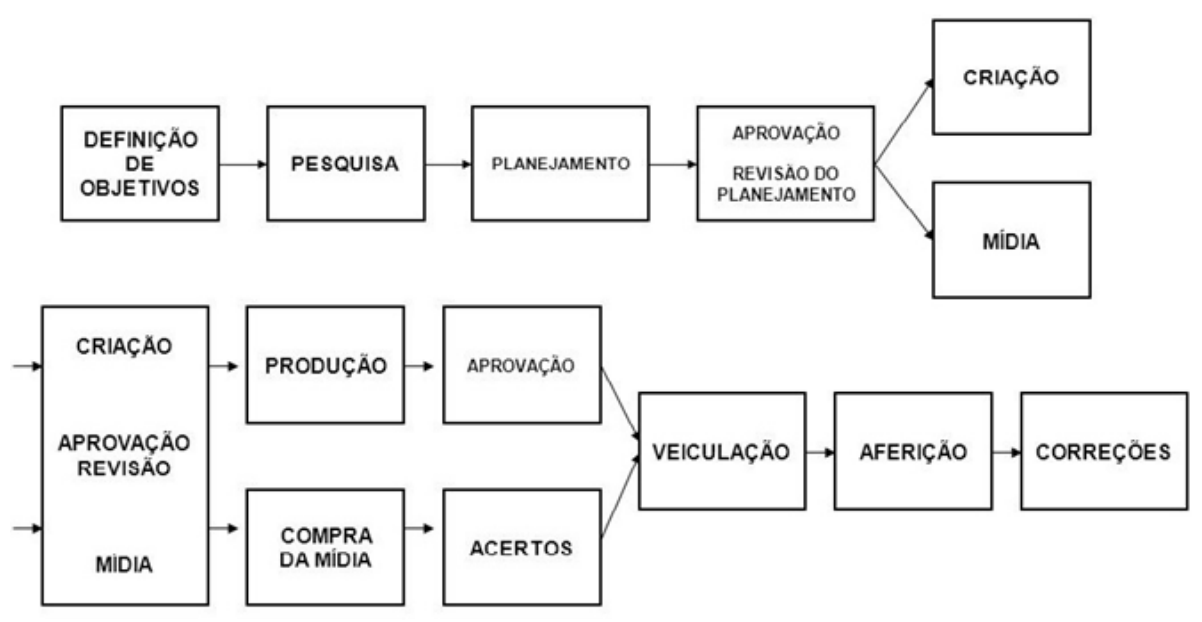


Fonte: Rafael Sampaio. Propaganda de A a Z. 3 Ed. Revista e Atualizada.2003, Pag. 34 ) Figura 1

De acordo com Rafael Sampaio (2003, Pag.31) para a criação de uma propaganda deve se seguir estas etapas:

Definição dos objetivos da propaganda:

- $\quad$ Com a definição da tarefa a ser cumprida, ou situação desejada, se vai informar, persuadir ou relembrar os consumidores (lançamento de produto, ideia, novo preço, incentivar, aumentar etc.).

Pesquisa:

- Realizando um trabalho de pesquisa, procurando informações sobre o consumidor, qual o seu público-alvo que você queira atingir, procurar saber de seus hábitos, estudar como ira reagir ao seu produto ou serviço, cultura a sociedade e o psicológico. Procurar sua concorrência de como ela age em seus consumidores. Nesta fase da pesquisa é interessante usar, uma das ferramentas de marketing analise de ambiente de marketing, para esta pesquisa seria interessante analisar o macro ambiente, onde as forças externas da empresa são variáveis, onde pode se afetar o objetivo a ser alcançado, com esta pesquisa pode se detalhar, e ter muitas informações. Segundo Kotler (2000, Pag.158) a fatores incontroláveis que o macro ambiente possui nele esta inserido seis forças principais: demográfica, econômica, natural, tecnológica, político-legal e sócio cultural.

Analise Demográfica: estudo da população. Muito estudado, pois nele esta envolvida as pessoas. Com esta analise pode se obter um relatório detalhado sobre a população. Analise Econômica: fatores econômicos que podem afetar o consumidor, afetar compra. Analise Natural: recursos como subsídios ou o que pode ser afetado.

Analise Tecnológica: pesquisas e desenvolvimento. Recurso essencial da para evolução da empresa. Analise políticolegal: Todo o desenvolvimento sendo afetado pelo ambiente político. Cada decisão dever ser cuidadosamente estudada.

Analise sócio cultural: varias tendências e forças externas podem surgir, sendo assim estudar a cultura, variáveis, economias, concorrência, preferências do consumidor.

Planejamento:

- $\quad$ Alinhar seus objetivos com um planejamento estratégico e analises, para ser realizado na propaganda; conhecer o mercado, os consumidores, concorrência.

Aprovação de planejamento e revisão: Criação e Mídia

- Criação: a criatividade uma peça importante na propaganda, criar algo novo que ninguém tenha visto antes, como conseguir atacar os olhos dos consumidores com a propaganda, algo que atinja diretamente o inconsciente. É algo que tem que ter interesse entre os consumidores. Aqui é destacado a geração de ideias.

- Mídia: Existem muitos meios de divulgação para o gestor de desfrutar do uso, sendo eles: televisão, rádio, panfletos, outdoor, internet, cartazes e muitos outros. Mas qual a escolha correta, ai cabe a uma analise de objetivo a ser cumprido, qual o público-alvo, estudar o ambiente que a empresa esta inserida. Um estudo de qual meio de comunicação irá atingir os a maior parte dos consumidores para seu determinado tipo de negocio.

Aprovação da criação e mídia:

- $\quad$ Os que fizeram o planejamento e o líder do projeto deve dar a palavra final da propaganda. Analises e revisão deve ser feita nesta etapa.

Produção e compra de mídia:

- $\quad$ Produção: Começa a produção das mensagens publicitárias (anúncios, fonogramas etc.) precisam ser criados para encaminhar aos veículos de comunicação. Nesta etapa utilizamos empresas ou pessoas especializadas em produção de mídia.

- $\quad$ Compra de mídia: compram de local ideal para a produção (estúdios, locais característicos) negociação de equipamento, recursos, condições de veículos de comunicação.

Veiculação: 
- $\quad$ Agora nesta etapa é escolhido qual o veiculo de comunicação será escolhido para ser contratado, como ira chegar até o consumidor, será por meio de publicação, colocando no ar, as mensagens publicitárias.

Aferição:

- $\quad$ Etapa final, onde se faz uma avaliação e analise se esforço da propaganda, pode ser pesquisada de varias maneiras sendo formas ou informal. Correções podem ser feiras para aumentar a eficácia e eficiência. Sendo assim nesta etapa se acumulam experiências sobre o mercado, os consumidores, estratégias. Com o aprendizado será muito importante nas próximas propagandas, como o mercado esta em constante mudança a propaganda precisa modificada cada vez mais.

\section{CONCLUSÃO}

O presente trabalho propôs demostrar por meio de pesquisas bibliográficas ferramenta de marketing , afim que o gestor comercial possa utilizar como auxilio na busca pelo conhecimento e sucesso da organização através da propaganda e publicidade, podendo assim atrair e fidelizar seu publico alvo.

Nos dias atuais o mercado de trabalho esta em constante evolução proporcionando o aumento de concorrência do ambiente que esta inserida, com os consumidores que estão cada dia mais exigentes e seletivos. Para conquistá-los é exigido das empresas novas estratégias, e técnicas para atrair consumidores obtendo uma saudável relação entre seus clientes internos e externos.

\section{REFERÊNCIAS BIBLIOGRÁFICAS}

Rafael Sampaio. Propaganda de A a Z. 3 Ed. Revista e Atualizada.2003

Arnold M. Barban; Steven M. Cristol: Frank J. Kopec. A essência do planejamento de mídia. São Paulo: Nobel ,2001.

Scharf, Edson Roberto. Administração na propaganda. Rio de Janeiro: Qualitymark ,2007.

Gade, Christiane. Psicologia do Consumidor e da Propaganda. São Paulo: EPU, 2003.

Tamanaha, Paulo. Planejamento de Mídia. São Paulo: Pearson Prentice Hall ,2010.

Kotler, Philip. Administração de marketing. São Paulo: Prentice Hall ,2002 10.ed. 